
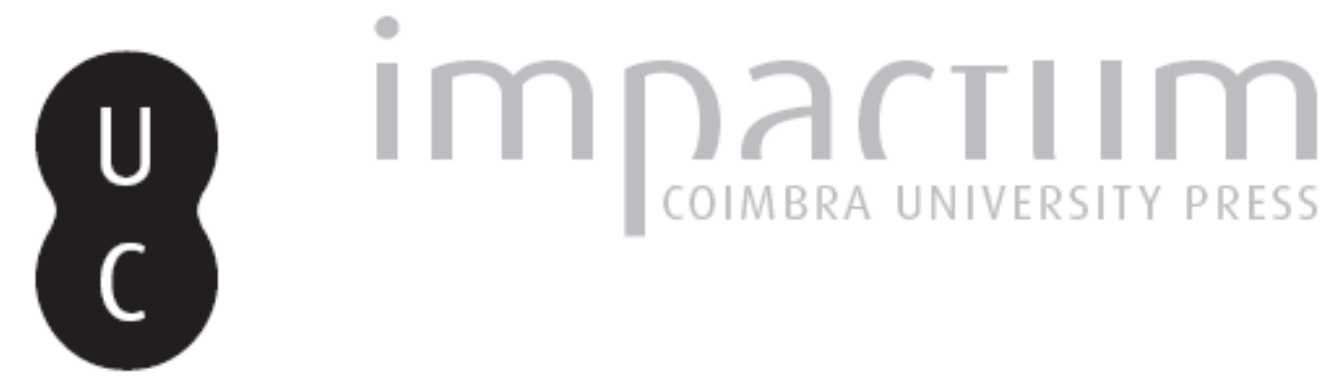

\title{
O 14 de novembro de 1980 na Guiné-Bissau visto pela imprensa portuguesa: análise comparativa
}

\author{
Autor(es): $\quad$ Gomes, Daniel Filipe Franco \\ Publicado por: Imprensa da Universidade de Coimbra \\ URL \\ persistente: \\ URI:http://hdl.handle.net/10316.2/35431 \\ DOI: \\ DOI:http://dx.doi.org/10.14195/0870-4147_45_21
}

Accessed : $\quad$ 26-Apr-2023 10:56:17

A navegação consulta e descarregamento dos títulos inseridos nas Bibliotecas Digitais UC Digitalis, UC Pombalina e UC Impactum, pressupõem a aceitação plena e sem reservas dos Termos e Condições de Uso destas Bibliotecas Digitais, disponíveis em https://digitalis.uc.pt/pt-pt/termos.

Conforme exposto nos referidos Termos e Condições de Uso, o descarregamento de títulos de acesso restrito requer uma licença válida de autorização devendo o utilizador aceder ao(s) documento(s) a partir de um endereço de IP da instituição detentora da supramencionada licença.

Ao utilizador é apenas permitido o descarregamento para uso pessoal, pelo que o emprego do(s) título(s) descarregado(s) para outro fim, designadamente comercial, carece de autorização do respetivo autor ou editor da obra.

Na medida em que todas as obras da UC Digitalis se encontram protegidas pelo Código do Direito de Autor e Direitos Conexos e demais legislação aplicável, toda a cópia, parcial ou total, deste documento, nos casos em que é legalmente admitida, deverá conter ou fazer-se acompanhar por este aviso.

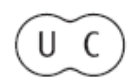




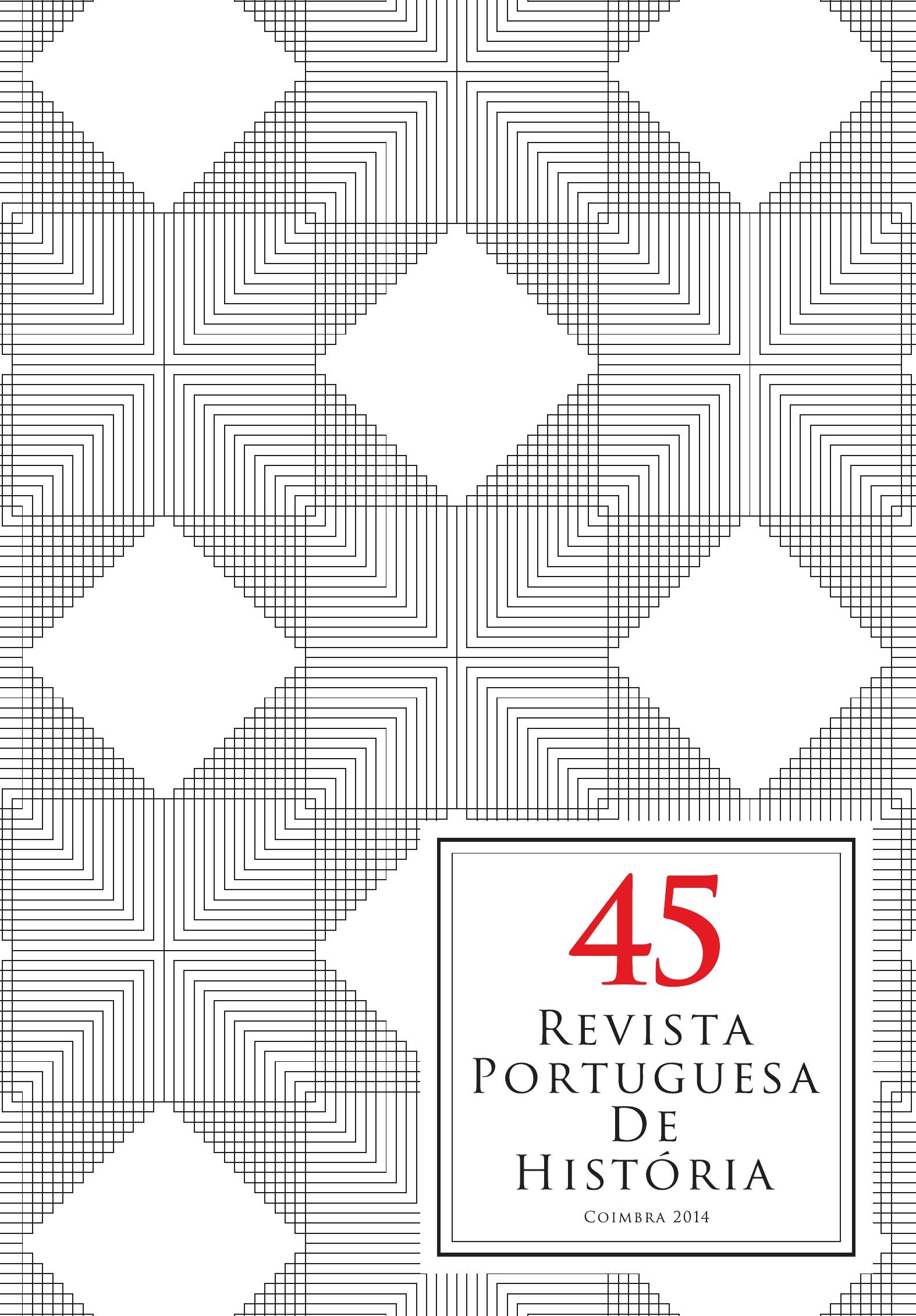




\title{
O 14 de Novembro de 1980 na Guiné-Bissau visto pela Imprensa Portuguesa. Análise Comparativa
}

\author{
The Portuguese Press and the November 14, 1980 \\ coup d'état in Guinea-Bissau. Comparative analysis
}

\author{
Daniel Filipe Franco Gomes \\ Investigador do Centro de Estudos Interdisciplinares do Século XX \\ da Universidade de Coimbra. Aluno de Doutoramento em Estudos Contemporâneos \\ do curso de $3{ }^{\circ}$ ciclo do CEIS20 da UC \\ daniel.ff.gomes@gmail.com
}

Resumo:

O 14 de Novembro de 1980 na Guiné-Bissau foi o primeiro golpe de Estado naquela ex-colónia portuguesa, após a independência. A tomada do poder por João Bernardo "Nino" Vieira surge num período conturbado da história da Unidade entre a Guiné-Bissau e Cabo Verde. Assim, foi objectivo deste trabalho analisar a forma como a imprensa escrita portuguesa viu, durante os dois últimos meses de 1980, o golpe na Guiné-Bissau, tendo em vista o conturbado período histórico que se vivia em Portugal e, ao mesmo tempo, no contexto internacional da época. Por outro lado, procurámos perceber de que forma a imprensa portuguesa abordou a questão da «unidade» neste momento decisivo para os dois Estados, de onde se destaca a polémica troca de mensagens entre "Nino" Vieira e Aristides Pereira, entretanto publicadas, parcialmente, pelo jornal Expresso.

Palavras chave:

Golpe de Estado; Guiné-Bissau; Imprensa Portuguesa.

\section{Abstract:}

The November 14, 1980 in Guinea-Bissau was the first coup d'état in that former Portuguese colony, after independence. João Bernardo "Nino" Vieira's takeover in Guinea-Bissau emerges in a crucial moment in the unity between Guinea-Bissau and Cape Verde. Thus, the objective of this work was to analyze the last couple of months of 1980 of the Portuguese written press and what they wrote about the coup. Internally, Portugal lived in a very troubled historical period, especially in the beginning of December; however, the international context was also very problematic. These issues were important to unveil the emphasis that the Portuguese written press gave to the coup in Guinea-Bissau, mostly about the main subjects around the coup, such as the «unity» between Guinea and Cape Verde, and the controversial messages exchanged between "Nino" Vieira and Aristides Pereira, partially published by the Expresso.

Keywords:

Coup d'État; Guinea-Bissau; Portuguese Press. 


\section{Introdução}

Em 14 de Novembro de 1980, sete anos após a Declaração da Independência de Madina do Boé, a República da Guiné-Bissau conheceu o seu primeiro abalo, quando João Bernardo "Nino" Vieira desencadeou um golpe de Estado que acabou com a chamada I República e com grande parte das suas estruturas político-administrativas, abrindo caminho para quase dezanove anos no poder. "Nino" Vieira que acabou por ser deposto de uma forma ainda mais dramática, após um sangrento período de guerra civil entre Junho de 1998 e Maio de 1999.

O golpe a as suas repercussões na Guiné-Bissau e, ao mesmo tempo, em Cabo Verde no contex to da «unidade», tiveram amplo reflexo em Portugal, em particular na imprensa escrita portuguesa, sobretudo devido às relações que o Estado português mantinha com o bissau-guineense. Neste sentido, o objectivo principal deste estudo é perceber, em termos qualitativos, de que forma alguns jornais portugueses abordaram o acontecimento, enquadrado num contexto histórico particular, procurando compreender de que forma foram tratados alguns dos temas centrais, que estiveram na origem e desenvolvimento dos acontecimentos.

Assim, depois de uma breve contextualização do período e de uma análise do que foi escrito acerca do avanço dos acontecimentos em Bissau e na Cidade da Praia, procuraremos perceber, então, de que forma alguns jornais portugueses abordaram a questão da «Unidade», como tema central e aglutinador no contexto ideológico do Partido Africano da Independência da Guiné e Cabo Verde (PAIGC). De seguida, abordaremos a forma como foram reproduzidas as posições dos principais agentes políticos envolvidos no golpe, nomeadamente "Nino" Vieira, Luís Cabral e Aristides Pereira. Com relevância surge também uma polémica troca de mensagens entre Bissau e a Praia, ou seja, entre o líder do movimento e o secretário-geral do Partido, Aristides Pereira, que foi abordada pela imprensa e que merecerá aqui uma referência. Finalmente, procuraremos perceber a problemática das influências externas, mas sobretudo a posição de Portugal e do Estado Português em todo o processo.

A análise empreendida refere-se aos dois meses finais do ano de 1980, acabando por incidir apenas nos acontecimentos relacionados com o golpe e desenvolvimentos imediatos, não avançando, por questões de tempo e, sobretudo, de espaço para a separação efectiva entre o PAIGC de Bissau e a secção da Praia, que terminaria com a fundação do Partido Africano da Independência de Cabo Verde (PAICV), em 20 de Janeiro de 1981. A pesquisa centrou-se, então, nos jornais Expresso, um semanário de grande alcance nacional, Diário 
de Notícias, um jornal diário nacional de grande tiragem, Diário de Lisboa e O Primeiro de Janeiro, dois diários ligados às duas principais cidades do país, de forma a podermos aferir de possíveis diferenças de abordagem aos acontecimentos, quiça numa perspectiva regionalista.

\section{2. $\mathrm{O} 14$ de Novembro num período histórico conturbado.}

O Movimento Reajustador, como acabou por ser denominado posteriormente pelo Conselho da Revolução da Guiné-Bissau, surge num contexto carregado de acontecimentos marcantes, quer a nível da vida política interna portuguesa, quer ao nível internacional, e que tiveram, obviamente, influência directa na abordagem que a imprensa escrita acabou por fazer acerca do golpe, que mereceu, mesmo assim, um acompanhamento consecutivo e quase ininterrupto.

Os meses de Novembro e de Dezembro de $1980^{1}$ contiveram alguns dos momentos mais marcantes da história contemporânea e, em particular, da história contemporânea portuguesa. Este período é marcado, na imprensa escrita, claramente pelas eleições presidenciais de 7 de Dezembro e respectiva campanha eleitoral, que recebeu a atenção mediática mais profunda, praticamente desde o Verão desse ano, através de uma vasta informação acerca dos candidatos e de todo o processo eleitoral. A 4 de Dezembro, escassos dias antes do acto eleitoral, mais um acontecimento marcante do Portugal contemporâneo haveria de encher as páginas dos jornais, a morte do Primeiro-Ministro Sá Carneiro e do Ministro da Defesa, Adelino Amaro da Costa, no famoso acidente de Camarate, que levaria a um período de grande interesse na imprensa portuguesa. Assim, no espaço de poucos dias acabaram por ter de cobrir o acidente, a reeleição de Ramalho Eanes e a escolha do novo governo, encabeçado, depois, por Francisco Pinto Balsemão².

No plano internacional, destaca-se a eleição de Ronald Reagan como Presidente dos Estados Unidos da América, eleito a 4 de Novembro com alguma surpresa para a imprensa nacional, e o recente conflito Irão-Iraque, que havia iniciado em finais de Setembro desse ano de 1980, e que tiveram direito a acompanhamento quase diário nos jornais analisados. Além disso, os suces-

${ }^{1}$ Como referimos, por uma questão de delimitação do objectivo do estudo, apenas consultámos estes meses dos referidos jornais, o que, mesmo assim, apresenta uma amostra relativamente grande, sobretudo no que respeita aos jornais diários.

${ }^{2}$ Refira-se, a título de curiosidade, que Francisco Pinto Balsemão foi o fundador do Semanário Expresso, um dos jornais analisados. 
sivos golpes de Estado na América Central e do Sul, nomeadamente em El Salvador, na Nicarágua ou no Chile, foram sucessivamente mencionados.

Para lá do plano político, outros dois acontecimentos foram alvo da atenção da imprensa escrita portuguesa. Um deles, com bastante destaque, foi o sismo que ocorreu em Itália a 23 de Novembro que vitimou cerca de três mil pessoas e, o outro, o assassinato de John Lennon a 8 de Dezembro, sendo que o famoso membro dos Beatles teve direito a partilhar as capas dos jornais, por exemplo do Diário de Lisboa, com Ramalho Eanes e o problema da continuidade da Aliança Democrática $(\mathrm{AD})^{3}$.

\section{A informação sobre o 14 de Novembro: perspectivas e argumentos.}

O objectivo deste artigo não é o de esclarecer sobre os acontecimentos, muito menos explicar pormenorizadamente o que foi o golpe de 14 de Novembro, ou Movimento Reajustador, como depois lhe chamou Nino Vieira, mas somente o de analisar o tratamento temático e qualitativo que a imprensa portuguesa efectuou sobre o assunto. Porém, antes de passarmos à análise da imprensa, é imprescindível apresentar uma breve contextualização do 14 de Novembro.

Com a independência de Cabo Verde, a 5 de Julho de 1975, no contexto da «unidade» o PAIGC repartiu a sua liderança entre Bissau e a Praia. O Secretário-Geral do Partido, Aristides Pereira, regressara a Cabo Verde a 21 de Fevereiro de 1975 e aí iria permanecer como líder do Partido e como chefe do Estado cabo-verdiano, enquanto o comandante Pedro Pires, ocuparia o cargo de primeiro-ministro. Por seu lado, em Bissau, Luís Cabral chefiava o governo guineense e liderava a secção do PAIGC naquele território.

Com a tomada do poder, o PAIGC deparou-se com uma série de desafios que irão percorrer todo o período da I República, e que estarão, mais ou menos, interrelacionados com o golpe de 14 de Novembro. Em primeiro lugar, devemos destacar que a chegada ao poder resulta de circunstâncias distintas nos dois territórios: se na Guiné-Bissau o PAIGC surge naturalmente como o único e legítimo representante do povo, resultado da luta armada de libertação, a verdade é que em Cabo Verde a tomada do poder teve de ser negociada com o poder colonial e, ao mesmo tempo, conquistada a outros agrupamentos políticos que reclamavam a participação na vida política, sobretudo a UDC

${ }^{3}$ Fundação Mário Soares/Documentos Ruella Ramos (FMS/DRR): (1980), "Diário de Lisboa", n. ${ }^{\circ}$ 20427, Ano 60, Terça, 9 de Dezembro de 1980, CasaComum.org, Disponível HTTP: http://hdl.handle.net/11002/fms_dc_2582 (2013-7-4). 
e a UPICV. Contudo, os grandes desafios que se colocavam ao PAIGC nos dois territórios eram, por um lado, a difícil tarefa de construção do Estado pós-colonial e, por outro, em termos político-ideológicos, a consecução do projecto da «Unidade», como veremos.

A forma como Amílcar Cabral estruturou todo o processo da luta armada e de conquista da independência foi, todo ele, notável, porém, segundo Lars Rudebeck, em relação ao processo de construção do estado pós-colonial, Cabral não o «tratou em profundidade» ${ }^{4}$, apresentando, conforme o mesmo autor indica, uma «tendência de considerar isso [a construção do Estado pós-colonial] como garantido» ${ }^{5}$. Apesar de em Cabo Verde se colocar o problema da sustentabilidade económica do território como principal entrave à construção do Estado, devido às suas características insulares e, sobretudo, às grandes carências da produção agrícola, a verdade é que na Guiné-Bissau as dificuldades apresentaram-se bem mais rigorosas. Isto deveu-se, em especial, à luta armada e ao longo período de guerra que todo o território viveu; à falta de meios humanos capazes de empreender a construção de um aparelho administrativo capaz, ainda mais quando uma parte importante das cúpulas do Partido era cabo-verdiana e regressou ao país de origem ${ }^{6}$; e, entre outros factores, a dificuldade em criar o sentimento de nação num Estado caracterizado pela multiplicidade de etnias.

Verificamos que o golpe de 14 de Novembro tem, assim, raízes profundas, que se encontram ainda na luta de libertação e desembocam nestas dificuldades, mas é a questão da «unidade» que irá acabar por ser o derradeiro fundamento de "Nino" Vieira para encetar o golpe. De facto, uma das principais características da revolta foi o seu carácter anticabo-verdiano, que desde sempre assombrou o Partido, que, embrenhado na sua esfera ideológica da «Unidade», sempre procurou contornar a verdadeira discussão acerca da histórica oposição entre os naturais da Guiné e os cabo-verdianos, estes utiliza-

\footnotetext{
${ }^{4}$ Rudebeck, Lars, «Uma Interpretação das Teorias de Cabral sobre a Democracia», in AAVV, Cabral No Cruzamento de Épocas. Comunicações produzidas no II Simpósio Internacional Amílcar Cabral, Organização Fundação Amílcar Cabral, CODESRIA e Fundação Mário Soares, Editora Alfa Comunicações, Praia, 2005, pág. 482.

${ }^{5}$ Idem.

${ }^{6}$ Para Silvino da Luz, um dos históricos do Partido, o facto de o Secretário-Geral do Partido ter passado a viver exclusivamente em Cabo Verde, é uma das falhas que aponta para a eclosão do 14 de Novembro de 1980. Vide entrevista a Silvino da Luz, conduzida por Leopoldo Amado, em 23 de Julho de 1998, na cidade do Mindelo, in Pereira, Aristides, O Meu Testemunho. Uma Luta, Um Partido, Dois Países, Versão Documentada, Editorial Notícias, Lisboa, 2003, pág. 625.
} 
dos durante décadas pelo poder colonial como intermediários entre as administrações e os indígenas.

Este antagonismo foi alimentado pelo aparelho colonial, em particular por António de Spínola, quando foi Governador e Comandante-Chefe da Guiné, entre 1968 e 1973. Durante esse período, Spínola procurou aplicar algumas medidas que visavam equilibrar o conflito, de acordo com o seu programa «Por uma Guiné Melhor» ${ }^{7}$, através do qual pretendia, entre outras coisas, reforçar a chamada Acção Psicológica, procurando acicatar junto da população guineense e de elementos do PAIGC as rivalidades e, sobretudo, o domínio cabo-verdiano dentro do partido. Na verdade, como admite Tcherno Djaló, «os Portugueses souberam explorar habilmente ${ }^{8}$ o facto de os cabo-verdianos ocuparem a maioria dos cargos de liderança dentro do Partido, originando relações tensas entre os dirigentes guineenses e cabo-verdianos. Outra das políticas com grande impacto no Estado pós-colonial, que Spínola incrementou em grande escala, foi a Africanização da guerra, ou seja, a mobilização das populações nativas para o serviço militar, quer na tropa regular, quer através das milícias, medidas que já vinham sendo aplicadas, embora com menos vigor, desde a governação de Arnaldo Schultz .

No pós-independência, a direcção do Partido, depois de ter negociado a independência de Cabo Verde, acabou por ficar dividida entre a Praia e Bissau, como já foi referido, numa liderança tripartida e pouco interligada, tornando a «Unidade» uma questão político-ideológica, ainda sem uma definição institucionalizada e sem estar formalmente presente numa constituição comum. De facto, quatro dias antes do golpe, a aprovação da nova Constituição da República da Guiné-Bissau pela Assembleia Nacional Popular, acabou por ser o rastilho do golpe de Estado comandado por "Nino" Vieira. Segundo António Duarte Silva, este novo texto constitucional «procurava materializar os objectivos inscritos no chamado "Programa Maior" do PAIGC, sobretudo quanto ao reforço da «unidade interna e da construção da Unidade Guiné-Cabo Verde» ${ }^{10}$, acrescentando este autor que «o texto desta nova Constituição guineense era

\footnotetext{
${ }^{7}$ Ver: Spínola, António de, Por Uma Guiné Melhor, Agência-Geral do Ultramar, Lisboa, 1970.

${ }^{8}$ Djaló, Tcherno, O Mestiço e o Poder. Identidades, Dominações e Resistências na Guiné, 1. edição, Colecção «O Facto e a Verdade», Edições Nova Vega, Lisboa, 201, pág. 266.

${ }^{9}$ Governador e Comandante-Chefe da Guiné entre 1964 e 1968.

${ }^{10}$ Silva, António E. Duarte, Invenção e Construção da Guiné-Bissau (Administração Colonial/Nacionalismo/Constitucionalismo), Edições Almedina, Coimbra, 2010, pág. 192.
} 
quase idêntico ao texto da Constituição da República de Cabo Verde, cuja aprovação e promulgação ocorrera pouco antes, em 5 de Setembro» ${ }^{11}$.

No entanto, a problemática constitucional não foi o único argumento utilizado pelos militares golpistas, no momento da tomada do poder.

Assim, da perspectiva da imprensa portuguesa o primeiro objecto da nossa análise será a forma como esta observou o golpe e, ao mesmo tempo, que argumentos foram expostos por ambos os lados, no sentido de perceber expectativas e apreensões que existiam naquele tempo presente, agora analisado historicamente.

Entrando, então, no objectivo primordial deste trabalho, em primeiro lugar convém esclarecer que, do ponto de vista analítico, o facto de o Expresso ser um semanário acarreta, desde logo, algumas características específicas, contudo, apesar de ser um dos principais jornais da praça portuguesa, a verdade é que acabou por ser aquele que mais tarde forneceu a notícia, apenas no dia 22 de Novembro, ou seja, oito dias depois do golpe. A particularidade de sair para as bancas semanalmente, forneceu a este órgão a possibilidade de poder abordar o tema com maior profundidade do que os diários, porém, a periodicidade da sua publicação acabou por dar a vantagem aos diários de referir o tema praticamente todos os dias durante quase dois meses, sendo que o Expresso acabou por ser, também, aquele que mais cedo esqueceu o assunto ou lhe prestou menor importância.

Provavelmente por razões editoriais, na tiragem do dia 15 de Novembro, um dia depois do golpe, não há uma única referência à Guiné-Bissau, quer pelo golpe quer por qualquer outro assunto, sendo que no mesmo dia já o Diário de Lisboa fazia manchetes com a tomada do poder por Nino Vieira. O 14 de Novembro foi, na realidade, um golpe militar que teve um efeito surpresa bastante grande, parece mesmo que inicialmente havia uma certa perplexidade e colocaram-se reticências em relação à informação que era publicada, o que fica documentado, por exemplo, pelo facto de, no mesmo dia em que anunciava o golpe, o Diário de Lisboa dar ainda destaque ao fim da visita a Bissau do Presidente da Mauritânia, Mohamed Haidalla, numa notícia completamente desligada da que anunciava o movimento militar. Em consonância, apenas no dia 16 de Novembro o Diário de Notícias e $O$ Primeiro de Janeiro dão a notícia do golpe em Bissau e da consequente saída do poder de Luís Cabral.

Inicialmente há uma certa tendência para apresentar favoravelmente Nino Vieira e o recém-formado Conselho da Revolução, na sequência dos argu-

${ }^{11}$ Idem. 
mentos que este apresentou para justificar o golpe. As justificações de Nino para o golpe, que podemos encontrar em todos os jornais, prendem-se com a presença dos cabo-verdianos no aparelho de Estado na Guiné-Bissau e com a questão da constituição, mas também se fala no falhanço das políticas económicas, ou simplesmente, na tentativa de «pôr fim às injustiças que o povo da Guiné-Bissau sempre tem sofrido» ${ }^{12}$.

Todavia, assim que a direcção do Partido em Cabo Verde respondeu a Nino Vieira, através de uma troca de mensagens que causarão alguma polémica, como veremos, também a imprensa escrita portuguesa começa a equilibrar as perspectivas, surgindo alguns artigos de opinião que questionam e que colocam em causa a legitimidade das justificações apresentadas por Nino. Apesar disso, o Expresso continua a ser o jornal que menos atenção confere à direcção do partido em Cabo Verde, acabando mesmo por sofrer alguns ataques verbais por parte de Pedro Pires, num órgão de informação oficial do regime da Praia.

É de destacar que apenas o Diário de Lisboa apresenta um «filme dos acontecimentos» ${ }^{13}$, acabando por ser o único que faz uma referência directa às implicações do golpe, nomeadamente no que refere à morte de alguns dirigentes do Partido e do Estado bissau-guineense, sobretudo António Buscardini e Otto Schacht, que tinham um passado histórico relevante na luta da libertação.

A informação diária sucedia-se, porém havia uma questão central em todo o processo e que se revelou transversal a todos os jornais analisados neste estudo: como é que fica a questão da «unidade»?

\section{A «Unidade» como princípio ideológico fundamental da existência do PAIGC.}

Desde a sua fundação, oficialmente em 19 de Setembro de $1956^{14}$, que o código genético do PAIGC se confunde com uma das suas principais carac-

${ }^{12}$ O Primeiro de Janeiro, n. ${ }^{\circ}$ 312, de 16 de Novembro de 1980.

${ }^{13}$ Diário de Lisboa: $n .{ }^{\text {o } 20410,} 17$ de Novembro de 1980.

FMS/DRR - Documentos Ruella Ramos: (1980), "Diário de Lisboa”, n. o 20410, Ano 60, Segunda, 17 de Novembro de 1980, CasaComum.org, Disponível HTTP: http://hdl.handle. net/11002/fms_dc_2913 (2013-7-3).

${ }^{14}$ No que concerne à data de fundação do PAIGC surgem algumas dúvidas. Apesar de historicamente se apontar o dia 19 de Setembro de 1956, em Bissau, para a constituição do partido com a sigla que hoje conhecemos, a verdade é que, ainda recentemente, o historiador Julião Soares Sousa contestou este facto, aferindo da impossibilidade de tal ter acontecido, alegando que Amílcar Cabral tão pouco se encontrava na Guiné nessa altura, indicando o mesmo dia, mas três anos mais tarde, como o da fundação do PAIGC. Há ainda fontes de informação portuguesas 
terísticas ideológicas, que constava inclusivamente na divisa do partido e que era a ideia de «unidade», presente em grande parte dos discursos de Amílcar Cabral.

A «unidade» era, deste modo, idealizada em três dimensões fundamentais: «na Guiné, em Cabo Verde e na Guiné e em Cabo Verde» ${ }^{15}$ e assumia uma importância extrema, não só no plano político-ideológico, mas também no plano socio-cultural. O que Amílcar Cabral pretendia era, num sentido mais amplo, criar a ideia de nação na Guiné, repartida num mosaico étnico extremamente complexo, e em Cabo Verde, sociologicamente mais homogéneo, contudo sem a experiência da luta armada, formadora de um sentimento independentista comum a toda a sociedade. Se estas duas dimensões continham, em si, um grau de dificuldade elevado, a verdade é que a terceira dimensão, a mais original, implicava a criação de uma entidade supranacional congregando guineenses e cabo-verdianos, que, sendo verdade que os uniam laços históricos, também não deixa de ser verdade que nem sempre essas ligações foram pacíficas.

Com o reconhecimento da independência da República da Guiné-Bissau por Portugal, em 10 de Setembro de 1974, e a consequente tomada do poder, o regime de Luís Cabral procurou centralizar o poder do novo Estado na capital, subvertendo as conquistas do período da luta armada, que se haviam centrado no espaço rural, com o apoio dos camponeses. Entre outros factores, esta centralização burocrática do aparelho de Estado reduziu drasticamente a participação popular, o que, aliado a um processo de reconstrução económico que privilegiou «o investimento industrial e o sector público» ${ }^{16}$, deixou as zonas rurais à mercê dos velhos poderes locais de tabanca. Paralelamente, com a falta de meios humanos capazes de assegurar a construção e crescimento do aparelho de Estado, o regime teve de procurar integrar o velho funcionalismo público do Estado colonial, assim como manter no poder «a high proportion of people of Cape Verdean origin in the Bissau-based government» ${ }^{17}$. Acumularam-se, assim, tensões que Luís Cabral foi incapaz de controlar, tendo atin-

militares que referem a fundação do partido em 1957, mas em Thiès, no Senegal, o que parece ser uma clara confusão com um partido senegalês com a mesma sigla PAI (Ordem de Batalha 1 -SIM/CTIG - 2. ${ }^{a}$ Repartição/QG/CTIG - Bissau, 31 de Outubro de 1967. Arquivo Histórico-Militar, 2. ${ }^{a}$ Div $-4 .^{a}$ Secção, n. ${ }^{\circ}$, Caixa 273).

${ }^{15}$ Cabral, Amílcar, Alguns Princípios do Partido, Seara Nova Editora, Colecção «De Leste a Oeste», Lisboa, 1974, pág. 19.

${ }^{16}$ Silva, António E. Duarte, Op. Cit., pág. 191.

${ }^{17}$ Chabal, Patrick, et all., A History of Postcolonial Lusophone Africa, Indiana University Press, Bloomington \& Indianapolis, 2002, pp. 250-251. 
gido o ponto mais alto em 1980, «when the party began to formulate national constitutional proposals which specified that Cape Verde's president should be Cape Verdean while introducing no restriction for Guinea-Bissau's president - a clear sign of potential continued Cape Verdean control in Bissau». ${ }^{18}$

Para além disso, o próprio secretário-geral do PAIGC, Aristides Pereira vinha já alertando para a passividade ideológica de alguns elementos do Partido, o que representava uma «fraqueza» que se manifestava através do «amiguismo, nepotismo, ostentação e ambição pessoal, numa demonstração de clara subordinação do interesse colectivo ao proveito próprio» ${ }^{19}$.

Associado a esta problemática, os militares revoltosos vão adicionar-lhe o mais polémico de tudo aquilo que está relacionado com o golpe, ao acusar a «unidade», ou de forma indirecta os cabo-verdianos, do fuzilamento sumário de cerca de 500 guineenses, enterrados em valas comuns, agora descobertas e apresentadas aos jornalistas de todo o mundo, onde jaziam opositores ao regime, nomeadamente aqueles que apoiaram uma tentativa de golpe de Malam Sanhá em 1978, e, sobretudo, os ex-comandos africanos, que haviam combatido pelas tropas portuguesas durante a guerra colonial e de libertação nacional.

O 14 de Novembro de 1980 revestiu-se, deste modo, de uma faceta claramente anticabo-verdiana, que a imprensa escrita portuguesa destacou amplamente, desde o seu início, que levou a questionar, inclusivamente, a viabilidade do próprio PAIGC como partido supranacional. O jornal $O$ Primeiro de Janeiro é o primeiro a dar-nos conta desta problemática central, logo a 16 de Novembro e nos dias seguintes, ao afirmar que Cabo Verde estaria de «prevenção», perante o golpe, cujo alcance ainda não era facilmente perceptível.

De facto, o matutino portuense dá bastante importância à perspectiva cabo-verdiana, afixando na primeira página do dia seguinte a condenação do governo da Praia ao golpe na Guiné-Bissau, antevendo que este poderia ameaçar a ruptura entre «os dois países que, sob a bandeira do PAIGC, caminhavam para a fusão numa só nação liderada por um partido comum» ${ }^{20}$. É necessário salientar que esta explicação parece-nos demasiado arrojada para a realidade

${ }^{18}$ Idem, pág. 251.

${ }^{19}$ Documentos Mário Pinto de Andrade (DMA)/Fundação Mário Soares (FMS): (1980-1980), "Especial Golpe de Estado - Unidade e Luta - Órgão de Informação do Conselho Nacional de Cabo Verde do PAIGC", n. . 3, Outubro de 1980 - Dezembro de 1980, CasaComum.org, Disponível HTTP: http://hdl.handle.net/11002/fms_dc_85541 (2013-6-27).

${ }^{20}$ O Primeiro de Janeiro, 17 de Novembro de 1980. Consultado na Biblioteca Geral da Universidade de Coimbra (BGUC). 
político-ideológica do Partido, por outras palavras, não é de crer que a «unidade» implicasse, a curto/médio prazo, a «fusão numa só nação», ao estilo do Tanganica e Zanzibar, até porque nunca ficou bem clara, mesmo por Amílcar Cabral, a forma como, no pós-independência, seria aplicado este princípio.

No que respeita ao Diário de Lisboa, este considera o 14 de Novembro de 1980 como «a segunda morte de Cabral» ${ }^{21}$, acrescentando que o próprio partido se encontraria «desfeito» com os acontecimentos ocorridos em Bissau. Este diário da capital é o único que dá particular relevância à visita a Bissau de Silvino da Luz, Ministro da Defesa de Cabo Verde, para se encontrar com Nino, de modo a poderem esclarecer as posições dos dois governos, cujas acusações se encontravam agora, a 21 de Novembro, bem mais moderadas, sobretudo da parte bissau-guineense. $\mathrm{O}$ ímpeto revolucionário diluíra-se e proclamava-se apenas como Movimento Reajustador, com o objectivo de mudar o líder do regime e os principais dirigentes responsáveis pela Segurança do Estado (Buscardini e Otto Schacht), afirmando que iriam seguir as directivas do Partido aprovadas no III Congresso, realizado na capital guineense em Novembro de 1977. Paralelamente ao encontro dos dois políticos em Bissau, este diário lisboeta, noticia a reunião do Conselho Nacional de Cabo Verde do partido, na Cidade da Praia, como uma das grandes «tentativas para salvar o PAIGC» 22.

No entanto, em contraponto com a moderação noticiada neste dia, a verdade é que no dia seguinte a «unidade» apresenta-se como irremediavelmente perdida com a denúncia dos fuzilamentos, consolidada com uma visita guiada a jornalistas e diplomatas acreditados em Bissau às valas comuns de Cumeré, Mansabá e Portogole. A acrescentar à denúncia dos fuzilamentos, os golpistas acusam Luís Cabral de ter ordenado as execuções, que foram, nas palavras de responsáveis pelo novo regime, «o preço da unidade com Cabo Verde» ${ }^{23}$. Mais grave ainda para o Partido seria a acusação, feita mais tarde, de que

${ }^{21}$ Diário de Lisboa: n. ${ }^{\circ} 20410,17$ de Novembro de 1980. Esta é, aliás, a opinião de Ana Maria Cabral, numa entrevista, conduzida por Leopoldo Amado, concedida em 2000. Vide Pereira, Aristides, O Meu Testemunho. Uma Luta, Um Partido, Dois Países, Versão Documentada, Editorial Notícias, Lisboa, 2003, pág. 344.

DRR/FMS: (1980), "Diário de Lisboa", n. o 20410, Ano 60, Segunda, 17 de Novembro de 1980, CasaComum.org, Disponível HTTP: http://hdl.handle.net/11002/fms_dc_2913 (2013-7-3).

${ }^{22}$ Diário de Lisboa: n. ${ }^{\circ} 20414,21$ de Novembro de 1980.

DRR/FMS: (1980), "Diário de Lisboa”, n. ' 20414, Ano 60, Sexta, 21 de Novembro de 1980 , CasaComum.org, Disponível HTTP: http://hdl.handle.net/11002/fms_dc_2929 (2013-7-3).

${ }^{23}$ Diário de Lisboa: $n .{ }^{\circ} 20415,22$ de Novembro de 1980.

DRR/FMS: (1980), "Diário de Lisboa", n. ${ }^{\circ}$ 20415, Ano 60, Sábado, 22 de Novembro de 1980, CasaComum.org, Disponível HTTP: http://hdl.handle.net/11002/fms_dc_2933 (2013-7-3). 
o secretário-geral, Aristides Pereira, teria conhecimento dos fuzilamentos, co-responsabilizando-o, automaticamente, pelas valas comuns encontradas.

De forma algo antagónica, ao mesmo tempo que distribuía responsabilidades por cerca de 500 mortes, Nino propunha a manutenção da «unidade com Cabo Verde numa base de igualdade ${ }^{24}$. Contudo, mesmo noticiando a possibilidade de o líder do Conselho da Revolução, agora o órgão máximo do novo regime, se poder encontrar com Aristides Pereira, a verdade é que o Diário de Lisboa, praticamente, encerra a problemática da «unidade» na edição de 13 de Dezembro, ao reconhecer que «ninguém admite já salvar a unidade com Cabo Verde» ${ }^{25}$, anunciando a descrença dos agentes políticos de Bissau em manter as bases ideológicas do Partido.

No mesmo tom dramático, o Diário de Notícias anunciava o «fim prematuro do projecto de unidade ${ }^{26}$, num artigo do enviado especial do jornal a Bissau, Luís Alberto Ferreira, no qual, de uma forma bastante lúcida, enumerava os diversos factores que estavam na origem da tomada do poder por Nino Vieira, desvalorizando as palavras dos dirigentes do novo regime que iam colocando o problema da nova Constituição no âmago da questão. Em consonância, o DN parece-nos ser o órgão de imprensa escrita analisado que mais questiona as posições do novo poder instituído na Guiné-Bissau em 14 de Novembro de 1980, todavia, a questão da «unidade» não assume um papel tão importante como, por exemplo, no Diário de Lisboa. De facto, acerca desta problemática, o DN dá alguma supremacia às posições cabo-verdianas, fazendo várias referências às críticas dos dirigentes da Cidade da Praia aos golpistas, incluindo a notícia de que Aristides Pereira terá enviado «mensagens a 20 chefes de Estado, incluído o Presidente Ramalho Eanes, manifestando a sua preocupação acerca dos acontecimentos na Guiné-Bissau» ${ }^{27}$.

Deste modo, a temática da «unidade» surge quase sempre de forma indirecta, inter-relacionada com o próprio Partido e, não raras vezes, associada às declarações provenientes de Cabo Verde. Na capa de 28 de Novembro surge um título que ilustra esta relação que o DN faz entre o PAIGC e a «unidade»,

${ }^{24}$ Idem.

${ }^{25}$ Diário de Lisboa: n. . 20431, 13 de Dezembro de 1980.

DRR/FMS: (1980), "Diário de Lisboa", n. . 20431, Ano 60, Sábado, 13 de Dezembro de 1980, CasaComum.org, Disponível HTTP: http://hdl.handle.net/11002/fms_dc_2590 (2013-7-4).

${ }^{26}$ Diário de Notícias, 17 de Novembro de 1980. Consultado na Biblioteca Geral da Universidade de Coimbra (BGUC).

${ }^{27}$ Diário de Notícias, 19 de Novembro de 1980. Consultado na Biblioteca Geral da Universidade de Coimbra (BGUC). 
ao afirmar causticamente que «parece nítido que o PAIGC morreu» ${ }^{28}$. Em termos comparativos, a forma como o Diário de Lisboa apresentou o fim da «unidade» acabou por ser bem mais sensato do que a forma como o fez o Diário de Notícias, que avançou muito para lá da encruzilhada ideológica em que o Partido se encontrava, para adiantar mesmo o seu próprio fim político.

A grande novidade que este diário acrescenta é a relação que faz do golpe com o próprio assassinato de Amílcar Cabral, quando coloca nas manchetes de 29 de Novembro um subtítulo em que se admite «que a morte de Amílcar Cabral se deva a divergências existentes no interior do PAIGC» ${ }^{29}$. Mesmo sabendo o nome de quem matou materialmente Amílcar Cabral, o membro do Partido, Inocêncio Kani, oficialmente é atribuída a responsabilidade moral à PIDE, todavia, recentes trabalhos académicos sugerem que esta hipótese avançada pelo DN em 1980 possa ter algum fundamento, referimo-nos em particular à biografia de Cabral da autoria de Julião Soares Sousa ${ }^{30}$. De facto, nesta edição de 29 de Novembro, Diogo Pires Aurélio, enviado especial do DN a Bissau, salienta que «tudo leva a crer que o fundador do PAIGC foi vítima das divergências existentes no seio do partido ${ }^{31}$, acrescentando que «já ninguém acredita que tenham sido as tropas portuguesas ${ }^{32}$, ao ventilar que o Presidente da República da Guiné-Conacry, Sékou Touré, poderia saber a verdade sobre o assunto, tendo mesmo, segundo o autor do artigo, «ameaçado [a Luís Cabral] fazer luz sobre o assunto» ${ }^{33}$.

Por fim, no que respeita ao que o semanário Expresso alvitra sobre a problemática da «unidade Guiné/Cabo Verde», numa longa reportagem efectuada pelo seu enviado especial a Bissau, Augusto de Carvalho, publicada na edição do dia 29 de Novembro, numa secção especial dedicada ao golpe na Guiné-Bissau, fica claro que também o Expresso advoga a probabilidade do fim da «unidade» no PAIGC. No entanto, coloca toda a ênfase nos fuzilamentos levados a cabo pelo regime de Luís Cabral, ao referir que «a unidade Guiné-

${ }^{28}$ Diário de Notícias, 28 de Novembro de 1980. Consultado na Biblioteca Geral da Universidade de Coimbra (BGUC).

${ }^{29}$ Diário de Notícias, 29 de Novembro de 1980. Consultado na Biblioteca Geral da Universidade de Coimbra (BGUC).

${ }^{30}$ Ver Sousa, Julião Soares, Amílcar Cabral (1924-1973). Vida e Morte de um Revolucionário

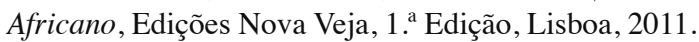

${ }^{31}$ Diário de Notícias, 29 de Novembro de 1980. Consultado na Biblioteca Geral da Universidade de Coimbra (BGUC).

${ }^{32}$ Idem.

${ }^{33}$ Idem. 
-Cabo Verde agoniza nos campos do Cumeré, Mansoa e Mansabá» ${ }^{34}$, numa clara alusão aos locais onde foram apresentadas as valas comuns.

O repórter deste semanário foi um dos que integrou a comitiva a quem foi denunciada in loco os locais onde estavam os cadáveres, vítimas das execuções, publicando uma descrição da viagem efectuada, assim como de uma entrevista a um homem que participara nos fuzilamentos e que servia agora de guia à comunidade internacional, o tenente Mário Costa Ribeiro. Este imputou responsabilidades directas nos massacres a alguns oficiais do Estado-Maior das Forças Armadas Revolucionárias do Povo (FARP), entre eles «Bobo Keita, Lúcio Soares, André Gomes [este militar viria a suicidar-se na prisão em finais de Dezembro], Julião Lopes, Abdoulay Bari (Presidente do Supremo Tribunal)». ${ }^{35}$

Apesar de o Expresso não dar grande importância à problemática da «unidade», a verdade é que vai ser o único órgão de comunicação social a ter acesso directo à correspondência trocada entre Nino Vieira e Aristides Pereira, cuja publicação em 20 de Dezembro irá criar alguma polémica com os dirigentes do PAIGC de Cabo Verde.

\section{A polémica em torno da publicação da correspondência entre Nino Vieira e Aristides Pereira.}

Apesar de apenas o Diário de Notícias assinalar a troca de mensagens entre Bissau e a Cidade da Praia, nomeadamente na sua edição de 19 de Novembro, todos os jornais analisados fazem um balanço permanente das relações entre os dois governos. No entanto, só o Expresso teve acesso à troca de mensagens que o DN referiu, tendo publicado, na edição de 29 de Novembro, algumas das que foram trocadas entre Nino Vieira e Aristides Pereira, o que causou sério desconforto em Cabo Verde, principalmente pelo facto de não ter sido autorizada essa publicação pelo secretário-geral do PAIGC.

Apesar de considerarmos que, no geral, a informação que passa neste semanário sobre o golpe de 14 de Novembro de 1980 não oferecer o necessário espaço editorial aos argumentos cabo-verdianos que, por exemplo, todos os diários analisados oferecem, a verdade é que o enviado especial do Expresso consegue alguns exclusivos importantes, demonstrando possuir contactos importantes em Bissau, em especial através de Nino Vieira.

${ }^{34}$ Expresso, n. ${ }^{\circ} 422$ - 29 de Novembro de 1980. Consultado em microfilme na Biblioteca Geral da Universidade de Coimbra (BGUC).

${ }^{35}$ Idem. 
Augusto de Carvalho, na introdução da extensa reportagem que faz na edição de 22 de Novembro, apresenta Nino Vieira como um amigo que, apenas dois dias antes do golpe, lhe confidenciara «que a situação no seu país lhe parecia um fruto podre, a que bastava dar um safanão para cair do galho que o suportava ${ }^{36}$, acrescentando que «esse amigo partilha hoje com outros doze o poder no seu país» ${ }^{37}$, concluindo que a liderar o golpe «estava, afinal, o homem que reunia todas as condições para dar um golpe de Estado, mas que ainda dias antes parecia recusá-lo: João Bernardo Vieira ${ }^{38}$. Estas afirmações devem decorrer, muito provavelmente, de encontros que ocorreram entre ambos, durante a estadia do líder golpista em Portugal, tendo-se confirmado inclusivamente que permaneceu no norte do país, em casa de um conhecido empresário do norte, e presidente do clube de futebol Boavista, Valentim Loureiro. Além disso, Augusto de Carvalho é também o único repórter da imprensa escrita portuguesa, pelo menos dos órgãos de comunicação analisados, que faz parte da comitiva que visita as valas comuns em Cumeré, Mansabá e Portogole.

Parecem-nos ser estas ligações que fazem com que o repórter do Expresso tenha conseguido o exclusivo acesso às mensagens trocadas entre Nino e Aristides Pereira. Contudo, acaba por colocar o semanário de Lisboa no centro dos ataques provenientes dos dirigentes do Partido na Cidade da Praia, que lançam uma edição de um órgão de informação oficial do Conselho Nacional de Cabo Verde do PAIGC, no qual Aristides Pereira e, sobretudo, Pedro Pires fazem duras críticas à imprensa portuguesa e, em particular, ao Expresso. O secretário-geral do Partido acusa «o ataque ao partido pela imprensa portuguesa e senegalesa ${ }^{39}$, num artigo cujo título deixava bem clara a posição de Cabo Verde em relação ao regime saído do 14 de Novembro, golpe considerado pelos dirigentes da Praia como mais grave ainda do que o assassinato de Amílcar Cabral. Por seu lado, Pedro Pires acusa o Expresso e, de forma implícita, os novos dirigentes de Bissau, uns por terem publicado informação confidencial sem terem tido autorização de uma das partes, os outros por terem fornecido essa mesma informação, denunciando ainda que «quem forneceu

${ }^{36}$ Expresso, n. ${ }^{\circ} 421$ - 22 de Novembro de 1980. Consultado em microfilme na Biblioteca Geral da Universidade de Coimbra (BGUC).

${ }^{37}$ Idem.

${ }^{38}$ Idem.

${ }^{39}$ DMA - FMS: (1980-1980), "Especial Golpe de Estado - Unidade e Luta - Órgão de Informação do Conselho Nacional de Cabo Verde do PAIGC', n. ' 3, Outubro de 1980 - Dezembro de 1980, CasaComum.org, Disponível HTTP: http://hdl.handle.net/11002/fms_dc_85541 (2013-6-27). 
as mensagens alterou a sequência e escondeu aquelas em que são frisadas as responsabilidades de $\mathrm{Nino}{ }^{40}$.

Na edição de 29 de Novembro, o semanário português revelava a correspondência trocada entre os dois líderes, mesmo apesar das grandes dificuldades de comunicação entre Bissau e o resto do mundo, denunciadas pelo repórter do Expresso. As cartas demonstravam, segundo Augusto de Carvalho, o clima de desconfiança crescente que existia entre os dois governos, nas quais sobressaem a reivindicação de Nino Vieira por uma maior igualdade entre a Guiné-Bissau e Cabo Verde, no contexto da «unidade», enquanto Aristides Pereira insistia na recriminação do golpe, repreendendo Nino «pela grave falta cometida contra a disciplina do Partido» ${ }^{41}$.

De facto, o jornal português publicava nesta edição apenas três das mensagens trocadas entretanto, duas de Nino Vieira e uma resposta de Aristides Pereira. Foi publicada a primeira mensagem de todas, a que foi enviada pelo líder do golpe de Estado, na qual procurava justificar, de forma breve, os motivos que levaram ao 14 de Novembro, para além de informar o secretário-geral de que o órgão que passava a substituir todos os órgãos constitucionais, entretanto dissolvidos, seria o Conselho da Revolução, que se iria manter fiel aos princípios do PAIGC. É curioso que, apesar das mortes de António Buscardini e de Otto Schacht, este último havia sido amigo pessoal de Nino e seu vizinho em Bissau, a mensagem falava na ausência de derramamento de sangue, o que, na realidade, não corresponderia à verdade.

A segunda mensagem publicada era uma resposta de Nino à carta de Aristides de 16 de Novembro, na qual é feito um ataque cerrado a Luís Cabral e à Constituição entretanto aprovada, extremando definitivamente as posições, com a irredutibilidade de Nino em recusar liminarmente o recuo do Movimento do 14 de Novembro, apesar de garantir a continuidade das «linhas e pensamento do saudoso Amílcar Cabral e dos fundamentos do Partido» ${ }^{42}$. Por fim, o Expresso publicava uma única carta de Aristides Pereira, na qual este faz um profundo lamento da decisão de Nino Vieira em desferir o golpe, colocando várias interrogações sobre o futuro do Partido e, simultaneamente, da «unidade», atribuindo ao líder do Movimento a responsabilidade de esclarecer todos os propósitos de tal acontecimento.

${ }^{40}$ Idem

${ }^{41}$ Expresso, n. ${ }^{\circ} 422$ - 29 de Novembro de 1980. Consultado em microfilme na Biblioteca Geral da Universidade de Coimbra (BGUC).

${ }^{42}$ Idem. 
Em contraponto, o órgão de informação «Unidade e Luta» do Conselho Nacional do PAIGC de Cabo Verde publica sete mensagens entre os dois líderes do Partido, entre 16 de Novembro e 16 de Dezembro de 1980, sendo que à data da publicação do n. ${ }^{\circ} 422$ do Expresso, de 29 de Novembro, teriam sido trocadas já cinco mensagens, pelo menos de acordo com os governantes da Praia. De facto, o semanário português publica apenas as três primeiras mensagens, ainda para mais trocando a sua ordem, uma vez que a que publica em terceiro lugar, a de Aristides Pereira, é, na verdade, a resposta à primeira mensagem de Nino, do dia 16 de Novembro.

Através de uma análise às restantes mensagens, parece que os dirigentes do PAIGC de Cabo Verde têm alguma razão quando afirmaram que a alteração da sequência e a omissão de algumas das mensagens tenderam a esconder aquelas em que o secretário-geral do Partido mais vincava a responsabilidade de Nino Vieira. Logo no início da resposta à segunda mensagem do dirigente de Bissau, Pereira ataca Vieira considerando que, após a leitura da carta anterior, «reina grande confusão no teu espírito a respeito das responsabilidades que cabem às diversas instâncias e aos dirigentes do PAIGC $\gg^{43}$, numa clara resposta às acusações Nino, que havia responsabilizado o secretário-geral do Partido de ter tido conhecimento dos fuzilamentos efectuados pelo anterior regime de Bissau. Pensamos que o ponto principal da defesa de Aristides Pereira surge quando lembra Nino que este era o Presidente do Conselho Nacional da Guiné, o «órgão máximo do executivo nacional do Partido na Guiné» ${ }^{44}$, continuando a acusá-lo de nunca ter discutido os problemas a nível dos órgãos internos do Partido, muito menos com o próprio secretário-geral.

As mensagens seguintes procuram marcar um encontro, Pereira sugere a Ilha do Sal e Nino finca posição e sugere Bissau. Devemos referir que pelo meio o Conselho da Revolução anunciou que a Guiné-Bissau iria julgar Luís Cabral e Aristides Pereira pelos fuzilamentos sumários ocorridos entre 1975 e 1980. Contudo, é através desta última troca de mensagens que percebemos uma grande mudança na atitude dos dirigentes da Cidade da Praia em relação a Bissau, e talvez possamos mesmo considerar que é aqui que conseguimos vislumbrar o fim da «unidade Guiné/Cabo Verde» e, ao mesmo tempo, a génese

${ }^{43}$ DMA - FMS: (1980-1980), "Especial Golpe de Estado - Unidade e Luta - Órgão de Informação do Conselho Nacional de Cabo Verde do PAIGC", n. ' 3, Outubro de 1980 - Dezembro de 1980, CasaComum.org, Disponível HTTP: http://hdl.handle.net/11002/fms_dc_85541 (2013-6-27).

${ }^{44}$ Idem. 
do próprio Partido Africano da Independência de Cabo Verde (PAICV), fundado a 20 de Janeiro de 1981, menos de um mês depois da última mensagem publicada neste órgão de informação. Até aqui, Aristides Pereira remeteu sempre as suas mensagens ao Presidente da Comissão Nacional da Guiné-Bissau, ou seja, a um responsável do Partido, contudo, na última mensagem de 22 de Dezembro, endereçou-a ao Presidente do Conselho da Revolução de Bissau, sendo que podemos depreender duas conclusões: uma é que existe, de certa forma, um reconhecimento daquele órgão como centro do poder na Guiné-Bissau, por outro lado, cremos que este pequeno pormenor marca, de facto, a ruptura definitiva da «unidade».

Para concluir, devemos referir que parece-nos que o Expresso acabou por ser, neste caso utilizado pelos dirigentes de Bissau, como forma de garantir legitimidade, pelo menos, perante Portugal, aproveitando o jornal também para conseguir alguns exclusivos importantes. Todavia, apesar de o que acabámos de referir ser algo especulativo, não podemos deixar de confirmar que o Conselho Nacional de Cabo Verde acabou por provar a denúncia da troca da ordem das mensagens publicadas no semanário português e a omissão das correspondências onde eram feitas os principais ataques à acção de Nino Vieira.

\section{Portugal e o Movimento Reajustador na perspectiva da imprensa escrita portuguesa.}

Apesar de ser, mais ou menos, consensual na imprensa que o golpe de 14 de Novembro de 1980, terá tido pouca ou nenhuma influência estrangeira, nomeadamente da União Soviética ou de Cuba, que mantinham conselheiros militares no território, quer mesmo dos Estados Unidos, cremos que a principal conexão que o golpe teve, em todos os momentos terá sido com Portugal. Com isto não estamos a afirmar dizer que o Estado português teve alguma influência na queda de Luís Cabral.

Esta ligação que estabelecemos reflecte-se em várias áreas e direcções. Neste sentido, a primeira grande preocupação da imprensa é a de dar conta da situação dos portugueses que permaneciam na Guiné-Bissau, mais propriamente na sua capital, facto que ainda hoje é comum encontrar nos meios de comunicação social quando se trata deste tipo de acontecimentos em países estrangeiros. Assim, logo no dia 16 de Novembro $O$ Primeiro de Janeiro apresenta declarações de Freitas do Amaral, na altura Vice-Primeiro-Ministro e Ministro dos Negócios Estrangeiros da AD, que confirma que «todos os 
portugueses estão bem ${ }^{45}$, declarações que foram reproduzidas, igualmente, na capa do Diário de Notícias do mesmo dia.

Para além desta comum preocupação, surgiram outros assuntos que consideramos menores, como, por exemplo, a notícia do diário portuense aqui analisado que dá conta do apoio dos muçulmanos de Lisboa a Nino Vieira. Contudo, há alguns temas comuns que merecem destaque, pela simultaneidade e pela repetição com que foram divulgados na imprensa escrita analisada. Uma das notícias comuns a todos os diários em análise, e que teve ampla cobertura, foi a passagem de Vasco Cabral - ex-ministro do Planeamento Económico da Guiné-Bissau e um dos mais ortodoxos do regime, que representava a facção marxista-leninista -, a caminho do exílio na Suécia. Depois de ter sido uma das vítimas do golpe, sofrendo alguns ferimentos, conseguiu, mesmo assim, chegar à embaixada da Suécia em Bissau, onde acabou por pedir asilo político. O Diário de Lisboa destaca este assunto durante dois dias consecutivos.

No que respeita ainda à vinda de implicados no golpe a Portugal, já no mês de Dezembro, é anunciada a visita de uma delegação guineense à antiga metrópole. O Diário de Lisboa dá conta desta visita de forma lacónica na edição de 10 de Dezembro, relatando a visita de uma delegação do novo poder guineense ao Porto, Lisboa, Aveiro e Coimbra para se reunir com guineenses, «apelando ainda para o regresso a Bissau do maior número possível de naturais daquele país ${ }^{46}$. Todavia, aquilo que o jornal não refere, é que os dirigentes de Cabo Verde, acusam esta delegação do Conselho da Revolução de procurarem fazer regressar a Bissau velhos opositores do PAIGC e mesmo guineenses que apoiaram o poder colonial durante a luta de libertação. Esta visita da delegação de Bissau é ainda noticiada no Diário de Notícias que acrescenta que virá nova delegação em Janeiro, desta vez representando o Conselho da Revolução «para contactar o Governo português e reforçar a cooperação entre os dois Estados $»^{47}$, demonstrando que Bissau estaria «a caminho de via mais moderada $»^{48}$, pelo menos em relação a Portugal, uma vez que «as

${ }^{45}$ O Primeiro de Janeiro, 16 de Novembro de 1980. Consultado na Biblioteca Geral da Universidade de Coimbra (BGUC).

${ }^{46}$ Diário de Lisboa: $n .^{\circ} 20428,10$ de Dezembro de 1980

DRR - Documentos Ruella Ramos: (1980), "Diário de Lisboa”, n. o 20428, Ano 60, Quarta, 10 de Dezembro de 1980, CasaComum.org, Disponível HTTP: http://hdl.handle.net/11002/ fms_dc_2584(2013-7-4).

${ }^{47}$ Diário de Notícias, 11 de Dezembro de 1980. Consultado na Biblioteca Geral da Universidade de Coimbra (BGUC).

${ }^{48}$ Diário de Notícias, 12 de Dezembro de 1980. Consultado na Biblioteca Geral da Universidade de Coimbra (BGUC). 
novas autoridades (muito mais claramente pró-portuguesas) não consideram Portugal, como país de pendor neocolonialista, e vêem na cooperação portuguesa a chave para os problemas» ${ }^{49}$.

$\mathrm{Na}$ verdade, as relações entre Portugal e a Guiné-Bissau parecem estar, na imprensa do mês de Dezembro, na ordem do dia. Neste sentido, o DN refere a intenção de Bissau em «estreitar relações com Portugal $\aleph^{50}$. Também o Expresso havia assinalado, um dia antes, na edição do dia 13 de Dezembro, este desejo do novo Governo guineense de «reforçar a cooperação com Portugal» ${ }^{51}$.

No entanto, esta aproximação entre os dois governos surge na sequência de algumas tensões anteriores, que incluíram algumas trocas de acusações e alguns suspeitas que, à partida, se revelaram infundadas. Num dos dias seguintes ao golpe, o Diário de Lisboa lança a notícia do possível envolvimento de uma rádio oficial portuguesa, a Radiodifusão Portuguesa, pelo menos na preparação do putsch de 14 de Novembro, afirmando mesmo haver «fortes indícios» ${ }^{52}$ desse envolvimento, principalmente porque essa rádio noticia o golpe muito antes dos restantes órgãos de informação portugueses, o que levantou suspeitas e surge mesmo a exigência de «uma explicação do Governo de Sá Carneiro» ${ }^{53}$. Este artigo, que não teve sequência noutros órgãos de informação escrita portugueses, chega mesmo a indicar que as informações fornecidas pelo canal 1 dessa rádio precederam os acontecimentos, acabando mesmo por apelidar tais informações de editoriais ao serviço dos golpistas, que, é bom relembrar, haviam permanecido em Portugal dias antes do movimento.

Esta notícia lançada pelo Diário de Lisboa volta a falar da estadia de Nino Vieira em casa de uma individualidade do norte, que pensamos tratar-se de Valentim Loureiro, que acabou por ser requisitado por alguns jornais para esclarecer algumas questões sobre o 14 de Novembro de 1980, dadas as conhecidas relações pessoais que mantinha com o novo líder da Guiné-Bissau.

${ }^{49}$ Idem.

${ }^{50}$ Diário de Notícias, 14 de Dezembro de 1980. Consultado na Biblioteca Geral da Universidade de Coimbra (BGUC).

${ }^{51}$ Expresso, n. ${ }^{\circ} 424$ - 13 de Dezembro de 1980. Consultado em microfilme na Biblioteca Geral da Universidade de Coimbra (BGUC).

${ }^{52}$ Diário de Lisboa: $n$. ${ }^{\circ}$ 20410, 17 de Novembro de 1980

DRR - Documentos Ruella Ramos: (1980), “Diário de Lisboa”, n. . 20410, Ano 60, Segunda, 17 de Novembro de 1980, CasaComum.org, Disponível HTTP: http://hdl.handle.net/11002/ fms_dc_2913(2013-7-3).

${ }^{53}$ Idem. 
Da imprensa analisada, curiosamente são os dois diários com menor abrangência que recorrem a esta fonte, o Diário de Lisboa e $O$ Primeiro de Janeiro. No diário lisboeta, em entrevista publicada logo a 18 de Novembro, Loureiro procura desfazer possíveis suspeitas de envolvimento no planeamento do golpe ou de possíveis futuros negócios na Guiné-Bissau, frisando a relação pessoal que tem com Nino e com Victor Saúde Maria, um dos homens fortes do novo regime. Em relação aos amigos guineenses, destaca a sua desilusão com o rumo que a governação tomou depois da independência, acrescentando que o que levou Nino a comandar o golpe «foi a recente concentração de poderes pelo dirigente Luís Cabral» ${ }^{54}$. No entanto, a informação que deu título a este artigo foi o facto de o novo líder guineense ter ficado indignado por «Sá Carneiro não o ter recebido» ${ }^{55}$, quando esteve em Portugal, ao contrário do que havia feito com Pedro Pires alguns dias antes, quando este regressava da Bélgica.

Já O Primeiro de Janeiro, na edição do dia 19 de Novembro, salienta, igualmente, a amizade de Valentim Loureiro com o comandante guineense, defendendo que o novo regime seria pró-ocidental e que precisariam do «apoio do Ocidente e, concretamente de Portugal, podendo no futuro vir a adaptar o modelo ocidental à sua própria maneira de ser africana ${ }^{56}$. Além disso, Valentim Loureiro afirma ainda que os «guineenses se sentiam colonizados» ${ }^{57}$, numa clara alusão à suposta supremacia cabo-verdiana na administração do Estado guineense, e denuncia a grande «corrupção governamental ${ }^{58}$, terminando a entrevista frisando também o seu completo desinteresse por eventuais negócios na Guiné-Bissau.

Finalmente, no que respeita a Portugal, resta saber que informação circulou na imprensa escrita portuguesa acerca das posições oficiais do Estado português. A este respeito, apenas o semanário Expresso publica notícias sobre as posições governamentais que surgem na edição de 22 de Novembro, noticiando que o governo português se encontra optimista, havendo a perspectiva

${ }^{54}$ Diário de Lisboa: n. ${ }^{\circ} 20411,18$ de Novembro de 1980

DRR - Documentos Ruella Ramos: (1980), "Diário de Lisboa”, n. o 20411, Ano 60, Terça, 18 de Novembro de 1980, CasaComum.org, Disponível HTTP: http://hdl.handle.net/11002/ fms_dc_2917(2013-7-3).

${ }^{55} \mathrm{Idem}$.

${ }^{56}$ O Primeiro de Janeiro, 19 de Novembro de 1980. Consultado na Biblioteca Geral da Universidade de Coimbra (BGUC).

${ }^{57}$ Idem.

${ }^{58}$ Idem. 
de «uma aproximação com Portugal» ${ }^{59}$. Parece mesmo que a posição portuguesa é mais entusiástica do que nos restantes países africanos lusófonos, por cujas reacções o governo português iria aguardar, para reconhecer o novo regime, uma vez que nesses países «as reacções parecem ser relativamente moderadas $»^{60}$. Esta posição é reforçada na edição da semana seguinte, numa entrevista ao embaixador português em Bissau, Meneses Cordeiro, que indica que o governo português não tem sequer «que reconhecer o novo regime» ${ }^{61}$, justificando que «Portugal não reconhece Governos mas Estados» ${ }^{62}$.

Apesar deste optimismo, surgem algumas questões que nos podem fazer duvidar desta posição adiantada pelo Expresso, sobretudo pelo facto de o governo português, com o apoio de Ramalho Eanes, se disponibilizar de imediato para receber Luís Cabral, o que parece colidir com a intenção, na altura, de julgar o presidente do Conselho de Estado deposto. Contudo, parece claro que a intenção das instâncias governamentais da antiga metrópole é a de aproveitar esta oportunidade para melhorar definitivamente as relações com a Guiné-Bissau, principalmente se o novo governo guineense se confirmar mais moderado.

\section{Conclusões}

A principal conclusão que podemos retirar deste trabalho de análise comparativa do 14 de Novembro de 1980 na imprensa portuguesa é que, apesar de surgir num momento conturbado, a nível externo e interno, principalmente devido às eleições presidenciais e ao acidente de Camarate que vitimou o Primeiro-Ministro e o Ministro da Defesa, a verdade é que podemos indicar que as notícias sobre o 14 de Novembro de 1980 se prolongaram durante o resto do mês de Novembro e quase todo o último mês desse ano, ultrapassando, inclusivamente, ao nível da quantidade de notícias, o acidente de Sá Carneiro e Adelino Amaro da Costa. Do que pudemos apurar, apenas as eleições presidenciais de 7 de Dezembro colheram maior atenção por parte da imprensa escrita analisada.

${ }^{59}$ Expresso, n. ${ }^{\circ} 421$ - 22 de Novembro de 1980. Consultado em microfilme na Biblioteca Geral da Universidade de Coimbra (BGUC).

${ }^{60}$ Idem.

${ }^{61}$ Expresso, n. ${ }^{\circ} 422$ - 29 de Novembro de 1980. Consultado em microfilme na Biblioteca Geral da Universidade de Coimbra (BGUC).

${ }^{62}$ Idem. 
Do período em estudo, que correspondeu aos meses de Novembro e Dezembro, que poderá parecer uma amostra pequena em termos cronológicos, mas que corresponde a cerca de quarenta e cinco publicações por diário, o que perfez, grosso modo, 135 jornais analisados, mais sete números do semanário Expresso, concluímos, igualmente, que os diários lisboetas são aqueles que mais referências têm aos acontecimentos na Guiné-Bissau, o Diário de Lisboa contendo 20 edições com notícias ou artigos de opinião sobre o assunto, enquanto em relação ao Diário de Notícias contabilizámos 29 edições.

Em consonância com o interesse verificado, está o facto de todos os jornais analisados terem tido a preocupação de destacar um enviado especial para cobrir as notícias sobre os acontecimentos, sendo de distinguir o do semanário, pelas reportagens exclusivas na Guiné-Bissau, apesar de o Expresso fazer poucas referências aos argumentos de Cabo Verde. Por outro lado, sabendo que a informação nos diários é distribuída de forma diferente, os enviados especiais dos jornais diários conseguiram contrabalançar de forma muito mais harmoniosa as informações de Bissau com as dos dirigentes do PAIGC de Cabo Verde, tendo surgido bastantes manchetes e primeiras páginas destacando claramente as posições cabo-verdianas.

Em relação aos conteúdos, a grande preocupação de toda a imprensa analisada prende-se com a questão da «unidade» e com o futuro do PAIGC, sendo de destacar a rápida percepção que houve de que o desmembramento do Partido estaria iminente ou se tornaria mesmo inevitável. Por outro lado, podemos destacar a grande originalidade dos intervenientes nestes meios jornalísticos, uma vez que conseguem publicar, inclusivamente, pequenas resenhas biográficas de elementos ligados ao golpe, como fizeram, por exemplo, com Rafael Barbosa ou com Vasco Cabral, duas figuras importantes, mas que nem sequer eram das principais cúpulas do Partido.

\section{Bibliografia}

AAVV, Cabral No Cruzamento de Épocas. Comunicações produzidas no II Simpósio Internacional Amílcar Cabral, Organização Fundação Amílcar Cabral, CODESRIA e Fundação Mário Soares, Editora Alfa Comunicações, Praia, 2005. Amado, Leopoldo, Guineidade \& Africanidade. Estudos, Crónicas, Ensaios e Outros Textos, Edições Vieira da Silva, 1. a edição, Lisboa, 2013.

Andrade, Mário Pinto de, Origens do Nacionalismo Africano. Publicações Dom Quixote, Lisboa, 1997.

Benot, Yves, Ideologias das Independências Africanas. Colecção Terceiro Mundo, 2 volumes, Livraria Sá da Costa Editora, 1. . edição portuguesa, Lisboa, 1981. 
Bernardo, Manuel Amaro, Guerra, Paz e Fuzilamento dos Guerreiros. Guiné 19701980, Edições Prefácio, Colecção «História Militar», Lisboa, 2007.

CABral, Luís, Crónica da Libertação, Edições «O Jornal», 1. edição, Lisboa, 1984.

Chabal, Patrick, Socialismo na Guiné-Bissau: problemas e contradições no PAIGC desde a independência, in Revista Internacional de Estudos Africanos N. 1 Janeiro/Junho 1984, dir. Jill R. Dias, subsidiada pela Fundação Calouste Gulbenkian, pp. 139-165.

Chabal, Patrick, et all., A History of Postcolonial Lusophone Africa, Indiana University Press, Bloomington \& Indianapolis, 2002.

Dualó, Tcherno, O Mestiço e o Poder. Identidades, Dominações e Resistências na Guiné, 1. a edição, Colecção «O Facto e a Verdade», Edições Nova Vega, Lisboa, 201, pág. 266.

Fernandes, Raúl Mendes, «Guinée-Bissau: Transition Démocratique?», Separata de L'Afrique Politique, 1994, pp. 81-91.

InduTA, Zamora, Guiné - 24 Anos de Independência (1974-1998), Prefácio de Jaime Nogueira Pinto, Hugin Editores, Lisboa, 2001.

Lopes, Carlos, Compasso de Espera - O Fundamental e o Acessório na Crise Africana, Edições Afrontamento, Porto, 1997.

Lopes, Carlos, Etnia, Estado e Relações de Poder na Guiné-Bissau, Edições 70, Colecção «Biblioteca de Estudos Africanos», Lisboa, 1982.

Lopes, Carlos, Guinea-Bissau. From Liberation Struggle to Independent Statehood, first published in 1987, in the UK by Zed Books Ltd., London; and in the USA by: Westview Press, Boulder, Colorado.

Lopes, José Vicente, Cabo Verde. Os Bastidores da Independência. Spleen Edições,

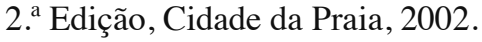

MacqueEn, Norrie, A Descolonização da África Portuguesa. A Revolução Metropolitana e a Dissolução do Império, Editorial Inquérito, Mem Martins, 1998.

Martins, José A. L., «Guiné-Bissau: da década de 60 à actualidade», in Africana, Revista Editada pelo Centro de Estudos Africanos da Universidade Portucalense, Porto, n..$^{\circ}$ 10, Março de 1992, pp. 81-143.

Nóbrega, Álvaro, A Luta pelo Poder na Guiné-Bissau, Edição do Instituto Superior de Ciências Sociais e Políticas da Universidade Técnica de Lisboa, Lisboa, 2003.

Pereira, Aristides, O Meu Testemunho. Uma Luta, Um Partido, Dois Países, Versão Documentada, Editorial Notícias, Lisboa, 2003.

Ribeiro, Sérgio, A Questão da Unidade no Pensamento de Amílcar Cabral, Prefácios de Vasco Cabral e Alfredo Moura, 1. ' Edição, Tricontinental Editora, Lisboa, 1983.

Sambu, Queba (Tenente-Coronel), Ordem para Matar. Dos Fuzilamentos ao Caso das Bombas da Embaixada da Guiné, Edições Referendo, Lisboa, 1989. 
Silva, António E. Duarte, «Movimentos de Libertação Nacional, Descolonização e Formação do Estado», in Estudos de Homenagem ao Prof. Doutor Jorge Miranda, vol. 1 - Direito Constitucional e Justiça Constitucional, Edição da Faculdade de Direito da Universidade de Lisboa, Coimbra Editora, 2012.

Silva, António E. Duarte, Invenção e Construção da Guiné-Bissau (Administração Colonial/Nacionalismo/Constitucionalismo), Edições Almedina, Coimbra, 2010, pág. 192.

Silva, António E. Duarte, O Constitucionalismo da Guiné-Bissau (1973-2005), Separata de «Estudos em Memória do Conselheiro Luís Nunes de Almeida», Tribunal Constitucional, Coimbra Editora, 2007.

SousA, Julião Soares, Amílcar Cabral (1924-1973). Vida e Morte de um Revolucionário Africano, Edições Nova Vega, 1. ${ }^{a}$ Edição, Lisboa, 2011.

Sousa, Julião Soares, Guiné-Bissau: A Destruição de um País. Desafios e reflexões para uma nova estratégia nacional, 1. a edição, Coimbra, 2012.

\section{Fontes}

Diário de Lisboa, in Arquivo Diário de Lisboa/Ruella Ramos - Fundação Mário Soares: http://casacomum.org/cc/arquivos?set=e_529\#!e_529.

Diário de Notícias, consultado na Biblioteca Geral da Universidade de Coimbra (BGUC), cota: B-23-1.

Expresso, consultado em microfilme na Biblioteca Geral da Universidade de Coimbra (BGUC).

O Primeiro de Janeiro, consultado na Biblioteca Geral da Universidade de Coimbra (BGUC), cota: B-4-1/48.

Arquivo Mário Pinto de Andrade (Fundação Mário Soares): http://casacomum.org/cc/ arquivos?set=e_3944.

Ordem de Batalha 1 - SIM/CTIG - 2. ${ }^{a}$ Repartição/QG/CTIG - Bissau, 31 de Outubro de 1967. Arquivo Histórico-Militar, 2. ${ }^{a}$ Div - 4. ${ }^{a}$ Secção, n. ${ }^{o}$, Caixa 273

\section{Fontes Impressas}

Cabral, Amílcar (Obras Escolhidas), A Arma da Teoria. Unidade e Luta I, Textos

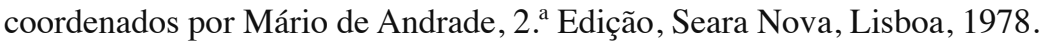

Cabral, Amílcar, Alguns Princípios do Partido, Seara Nova Editora, Colecção «De Leste a Oeste», Lisboa, 1974.

Cabral, Amílcar, Guiné-Bissau - Nação Africana Forjada na Luta, Textos de Amílcar Cabral n. ${ }^{\circ}$ 1, Coordenação de J. Camacho e Joel Silveira, Publicações Nova Aurora, Lisboa, 1974. 
Cabral, Amílcar, P.A.I.G.C. Unidade e Luta, Textos de Amílcar Cabral n. ${ }^{2}$, Publicações Nova Aurora, Lisboa, 1974.

Cabral, Amílcar, Textos Políticos, Edições Afrontamento, Porto, 1974.

Sínola, António de, Por Uma Guiné Melhor, Agência-Geral do Ultramar, Lisboa, 1970. 